\title{
BMJ Open Patient characteristics and disease burden of alopecia areata in the Danish Skin Cohort
}

\author{
Yuki M F Andersen, ${ }^{1}$ Lea Nymand, ${ }^{1}$ Amy M DeLozier, ${ }^{2}$ Russel Burge,${ }^{2}$ \\ Emily Edson-Heredia, ${ }^{2}$ Alexander Egeberg (D) ${ }^{1}$
}

To cite: Andersen YMF, Nymand L, DeLozier AM, et al. Patient characteristics and disease burden of alopecia areata in the Danish Skin Cohort. BMJ Open 2022;12:e053137. doi:10.1136/ bmjopen-2021-053137

- Prepublication history and additional supplemental material for this paper are available online. To view these files, please visit the journal online (http://dx.doi.org/10.1136/ bmjopen-2021-053137).

Received 06 May 2021 Accepted 23 January 2022

\section{Check for updates}

(c) Author(s) (or their employer(s)) 2022. Re-use permitted under CC BY-NC. No commercial re-use. See rights and permissions. Published by BMJ.

${ }^{1}$ Department of Dermatology, Bispebjerg Hospital, Copenhagen, Denmark ${ }^{2}$ Global Health Outcomes, Eli Lilly and Company, Lilly Corporate Center, Indianapolis, Indiana, USA

\section{Correspondence to} Yuki M F Andersen; yuki.maria.fukuda.andersen. 01@regionh.dk

\section{ABSTRACT}

Purpose Alopecia areata $(A A)$ is a common disorder of patchy hair loss which carries a substantial psychological burden for patients. The current understanding of $A A$ prevalence, disease course and burden is limited, and further research is needed to improve patient care. This prospective cohort of AA patients within the Danish Skin Cohort was established to provide data that can serve as a tool in future studies of for example, AA epidemiology and disease burden.

Participants A total of 1494 patients with dermatologistverified $A A$ were included in the cohort. Patients were invited and included through electronic or phone-based questionnaires. Information regarding demographics, biometrics, lifestyle factors, skin type, AA onset and development, health-related quality of life and selfreported severity assessment was collected.

Findings to date The mean (SD) age of AA onset was 32.7 (17.6) years. The mean body mass index and history of cigarette smoking was comparable with the general population. The majority $(92.5 \%)$ of participants were Caucasian. In total, $72.4 \%$ of patients received their diagnosis by a physician within a year after onset of symptoms, and $66.9 \%$ reported to still have symptoms of AA within the past year. A total of $12 \%$ reported to have a first-degree family member with $\mathrm{AA}$. In total, $31.4 \%$ of patients were missing all or nearly all hairs on their scalp, $32.2 \%$ had no or barely no eyelashes and $36.2 \%$ had no or barely no eyebrow hairs. Overall, most patients $(55.7 \%)$ did not experience irritated eyes, but 30\% reported slight eye irritation and $47.2 \%$ reported no damage to finger nails or toenails.

Future plans Observational studies regarding comorbidities, psychosocial burden of AA and efficacy of pharmacological interventions will be carried out and additional data will be linked from nationwide registries of routinely collected data. Furthermore, follow-up survey data will be added for longitudinal analyses.

\section{INTRODUCTION}

Alopecia areata (AA) is a common hair loss disorder with a life-time prevalence estimated to be approximately $2 \%$ in the USA. ${ }^{2}$ The condition affects both children and adults and typically presents as well-demarcated patches of hair loss in the scalp without significant visible inflammation or scarring.

\section{Strengths and limitations of this study}

This cohort was interviewed by trained professionals in a standardised manner.

- The diagnosis of alopecia areata was verified by dermatologists in all patients.

- Patients were not informed of the topic and contents of the projects until they agreed to participate, thereby reducing participation bias.

- Patients were not interviewed about comorbidities, since such information can be obtained by linking patients' responses with nationwide registries in Denmark.

- Risk of recall bias is a limitation as the cohort is based on patient interviews.

AA may progress to involve the entire scalp (alopecia totalis) or all scalp and body hairs (alopecia universalis). ${ }^{3}$ The course of AA is unpredictable, and regrowth and relapse may occur, alternately. The condition is furthermore associated with atopic predispositions and various autoimmune diseases, in particular thyroid disease and vitiligo. ${ }^{4}$ The exact pathophysiology of AA is unknown, however it is considered to be a T-cell mediated autoimmune condition where hair follicles enter the telogen phase (resting phase) prematurely, resulting in hair loss. ${ }^{56}$

Although AA is a common condition in dermatological practice, understanding of prevalence, prognosis and impact on patients' lives remain scarce and the condition is understudied compared with for example, atopic dermatitis and psoriasis. A detailed description of patients with $\mathrm{AA}$ and establishment of a prospective cohort will enable better understanding of AA and secure an increased recognition within the field of dermatological research. Furthermore, a well-described patient cohort may serve as a tool in future research and assessment of efficacy of future emerging therapies. The aim of the current paper was to present the establishment of 
a new AA cohort within the Danish Skin Cohort and to describe patient demographics and characteristics.

\section{COHORT DESCRIPTION}

This study was a population-based cross-sectional study using data from the extended Danish Skin Cohort. Information regarding patient characteristics, disease onset, severity and patient-reported outcomes (PRO) were collected using questionnaires or structured interviews.

\section{The Danish Skin Cohort}

The Danish Skin Cohort was established in 2018 to study the prevalence, morphology and burden of skin diseases in Denmark. ${ }^{7}$ The cohort originally consisted of three independent samples. Sample A representing a random sample of general population adults in Denmark. Samples B and C representing groups of patients with a dermatologist verified plaque psoriasis, and atopic dermatitis, respectively. All participants in this prospective cohort were adults ( $\geq 18$ years) at the time of inclusion. In 2020, the Danish Skin Cohort was expanded to also include patients with AA, hidradenitis suppurativa and rosacea. Patients with AA were identified using the Danish National Patient Registry. The registry contains information on all hospital contacts (both inpatient and outpatient) in Denmark, as well as a number of private practice dermatology clinics. Each visit is coded with a diagnostic code based on the International Classification of Diseases (ICD) system. ${ }^{8}$ All patients with an ICD-10 code for AA recorded in the Danish National Patient Registry at least once during adulthood (ie, after their 18th birthday) were identified and invited to participate in the cohort. Participants were not informed that the research project was related to skin diseases until they had agreed to participate and were simply informed that the research was 'regarding people in the Danish population'. This was to reduce the risk of participation bias. Study individuals had the opportunity to withdraw from participation on accepting the invitation, and throughout the study. A total of 3198 adults with a diagnosis of AA were invited to participate.

\section{Patient and public involvement}

Patients were not involved in the development of the research questions or outcome measures, but all responses to these interviews were provided by AA patients.

\section{Patient interviews}

All communications from the government and official institutions in Denmark are sent to citizens to a personal and secure digital mailbox. Citizens are notified through a text message or email and they are obliged to check the mailbox on a regular basis. Individuals who were eligible to participate in the Danish Skin Cohort received an invitation to participate and were interviewed through a digital questionnaire. In case of non-response, individuals were sent a reminder after 1 week, and were contacted by phone or mail up to a total of five times. In case of a phone interview, participants were interviewed in a structured manner by professional researchers.

Information on patient demographics including age at participation, sex, height in centimetre, weight in kilogram, smoking history and quantity, current alcohol consumption, level of physical activity and Fitzpatrick skin type (range 1-5) was obtained. Other variables included age of AA onset, time from onset to diagnosis by physician, time from onset to dermatologist referral, AA symptoms and activity during the past 12 months, family history of AA, episodes of flares or worsening in AA symptoms during the past 12 months, seasonal variation in symptoms and the affected hair loss in percentages. Current self-perceived severity of AA symptoms was recorded using a Numeric Rating Scale (NRS) from 0 to 10 , where 10 represents the highest degree of severity. Additional PROs included Dermatology Life Quality Index (DLQI), Work Productivity and Activity Index (WPAI), EuroQoL 5 Dimensions 5 Levels (EQ-5D-5L) and the Multidimensional Fatigue Inventory-20 (MFI-20). Additional PRO measures included assessment of nail appearance, eye irritation, affection of eye lashes, involvement of eyebrows and scalp hair assessment. ${ }^{9}$ A measure of eye irritation, rather than a measure of dry eyes, was included since this measure was specifically developed and used in clinical trials of novel AA therapies, thus enabling direct comparison with clinical trial results (NCT03899259). A full list of the obtained information is available from online supplemental table 1.

\section{Statistical analysis}

Characteristics of patients with AA were presented using summary statistics. Continuous variables with a normal distribution were presented as means and SD, while medians and IQR were presented for non-normal continuous variables. Categorical variables were presented as frequencies and percentages. As the data were purely descriptive, no test for significance was carried out.

\section{Patient demographics}

A total of 1494 patients with AA accepted the invitation and were included. The mean age (SD) at inclusion was 51.3 (16.0) years, with a strong female predominance of $67 \%$ (table 1). The mean age (SD) at AA onset was 32.7 (17.6) years (table 2). Previous epidemiological studies have shown contradicting results regarding the gender distribution among AA patients, where some studies show an equal distribution, while others show a greater representation of either sexes. ${ }^{1210}$ The gender distribution may vary according to study population and study design. Our observation may partially reflect a higher awareness of hair loss among women. Furthermore, the skewed distribution may represent different response rates in different demographic groups, where middle-aged women tend to have higher response rates than young men, for example. The reported age of AA onset in our cohort is similar to previous reports, where the majority of patients tend to experience first onset of AA before the age of 40. A literature review has estimated that the mean age of onset of 
Table 1 Patient characteristics

\begin{tabular}{|c|c|}
\hline & \multirow{2}{*}{$\begin{array}{l}\text { Alopecia areata } \\
n=1494\end{array}$} \\
\hline & \\
\hline Age at inclusion, mean (SD) & $51.3(16.0)$ \\
\hline Female & $1003(67.1)$ \\
\hline Male & $491(32.9)$ \\
\hline \multicolumn{2}{|l|}{ BMI, n (\%) } \\
\hline$<18.5$ & $34(2.3)$ \\
\hline $18.5-25$ & 705 (47.2) \\
\hline$>25-30$ & $522(34.9)$ \\
\hline$>30-35$ & $161(10.8)$ \\
\hline$>35$ & $72(4.8)$ \\
\hline BMI, mean (SD) & $25.8(5.2)$ \\
\hline \multicolumn{2}{|l|}{ Smoking status, n (\%) } \\
\hline Current daily smoker & $205(13.7)$ \\
\hline Current occasional smoker & $78(5.2)$ \\
\hline Former smoker & $508(34.0)$ \\
\hline Never smoker & $703(47.1)$ \\
\hline \multicolumn{2}{|l|}{ Physical activity, n (\%) } \\
\hline Sedentary & $294(19.7)$ \\
\hline Moderate & $814(54.7)$ \\
\hline Vigorous & $362(24.3)$ \\
\hline Athletic & $19(1.3)$ \\
\hline \multicolumn{2}{|l|}{ Fitzpatrick skin type, n (\%) } \\
\hline 1 & $106(7.1)$ \\
\hline 2 & $605(40.5)$ \\
\hline 3 & $671(44.9)$ \\
\hline 4 & $97(6.5)$ \\
\hline 5 & $15(1.0)$ \\
\hline \multicolumn{2}{|l|}{ DLQI, n (\%) } \\
\hline $0-2$ & $1128(75.5)$ \\
\hline $3-5$ & $220(14.7)$ \\
\hline $6-9$ & $83(5.6)$ \\
\hline $10-14$ & $36(2.4)$ \\
\hline $15-19$ & $13(0.9)$ \\
\hline$\geq 20$ & $14(0.9)$ \\
\hline DLQI, median (IQR) & $1(0-2)$ \\
\hline
\end{tabular}

BMI, Body Mass Index; DLQI, Dermatology Life Quality Index.

AA is between 25.2 and 36.3 years. ${ }^{2}$ Hair loss in children, adolescents and young adults often has a big impact on the patients' self-esteem, and therefore less likely to be affected by recall bias. ${ }^{11}$

\section{FINDINGS TO DATE}

\section{Body mass index and lifestyle factors}

The mean (SD) BMI in the AA population was 25.8 (5.2). According to WHO classification of BMI, $2.3 \%$ were classified as underweight, $47.2 \%$ as normal weight, $34.9 \%$ as overweight $10.8 \%$ as obese and $4.8 \%$ as morbidly obese.
Table 2 History of alopecia areata

Alopecia areata $n=1494$

Age at $A A$ onset, mean (SD)

$32.72(17.6)$

Years from onset of symptoms to diagnosis by a general practitioner

\begin{tabular}{|c|c|}
\hline Mean (SD) & $0.99(3.4)$ \\
\hline Less than 1 year, n (\%) & $105(72.4)$ \\
\hline One year, n (\%) & $26(17.9)$ \\
\hline Two or more years, $\mathrm{n}(\%)$ & $14(9.7)$ \\
\hline \multicolumn{2}{|c|}{$\begin{array}{l}\text { Years from onset of symptoms to diagnosis by a } \\
\text { dermatologist }\end{array}$} \\
\hline Mean (SD) & $1.18(4.5)$ \\
\hline Less than 1 year, $\mathrm{n}(\%)$ & $671(68.5)$ \\
\hline One year, n (\%) & $198(20.2)$ \\
\hline Two or more years, $\mathrm{n}(\%)$ & $110(11.2)$ \\
\hline \multicolumn{2}{|c|}{ Did you have AA within the last 12 months? $\mathrm{n}(\%)$} \\
\hline Yes & $741(66.9)$ \\
\hline \multicolumn{2}{|c|}{ Patient reported current severity of AA, NRS 0-10 } \\
\hline Mean (SD) & $7.37(3.2)$ \\
\hline Median (IQR) & $9(5-1)$ \\
\hline \multicolumn{2}{|l|}{ Family history of $\mathrm{AA}, \mathrm{n}(\%)$} \\
\hline Siblings & $56(5.1)$ \\
\hline Mother & $47(4.2)$ \\
\hline Father & $59(5.3)$ \\
\hline Grand parents & $43(3.9)$ \\
\hline Children & $32(2.9)$ \\
\hline At least one first degree family with $A A$ & $179(12.0)$ \\
\hline
\end{tabular}

.AA, alopecia areata; NRS, Numeric Rating Scale.

Almost half of the patients had never smoked (47.1\%), while $34.0 \%$ and $19.0 \%$ were former and current smokers, respectively. Furthermore, $54.7 \%$ rated themselves to having a moderate physical activity level, while $24.3 \%$ and $1.3 \%$ reported a vigorous and athletic physical activity level, respectively. Finally, 19.7\% reported a sedentary lifestyle.

In comparison, patients from the Danish Skin Cohort with psoriasis have a slightly higher mean (SD) BMI of 27.5 (6.5), while patients with atopic dermatitis have a similar mean (SD) BMI of 25.9 (5.6) (data on file). ${ }^{12}$ The prevalence of cigarette smoking in patients with AA was comparable with the general population and lower than in patients with psoriasis in the Danish Skin Cohort. ${ }^{12}$ The psychological stress of having AA may influence patients' smoking habits, however the low mean age at onset could explain why AA patients resemble the general population. Traditionally, AA is not considered a disease associated with obesity and lifestyle-related risk factors like, for example, patients with psoriasis. The current evidence on the cardiovascular risk in patients with AA is limited and 
studies show conflicting results. ${ }^{13-15}$ Cigarette smoking was found to be associated with an increased risk of AA in a recent cohort study from Taiwan, however further studies are needed to establish a relationship. ${ }^{16}$

\section{Fitzpatrick skin type}

We found that the majority $(92.5 \%)$ of patients with AA in our cohort reported a Fitzpatrick skin type 1, 2 or 3. Only $6.5 \%$ and $1.0 \%$, respectively, reported a skin type 4 and 5 . To the best of our knowledge, no data on skin type distribution is published on the Danish general population, therefore we lack a comparison group for this outcome.

Racial disparities seem to exist in the prevalence of AA, and recent US epidemiologic studies have reported that African Americans have a higher odds of AA, while Asians have a lower odds of AA compared with Caucasians. ${ }^{17} 18$ Furthermore, differences in disease prevalence according to geographical location and ethnicity is well described in autoimmune diseases such as lupus erythematosus, rheumatoid arthritis and multiple sclerosis. ${ }^{19} 20$ The Danish population is considered to be primarily Caucasian, thus not representative for investigating this characteristic of AA.

\section{Dermatology Life Quality Index}

Patients with AA in our cohort reported a mean (SD) DLQI of 2.1 (3.7) and median (IQR) DLQI of 1 (0-2). DLQI is a broadly used and validated outcome to measure the impact of dermatological diseases on patients' quality of life. The score ranges from 0 to 30 , where a high score signifies a high impact on health-related quality of life. We found a remarkably low DLQI in our AA cohort. One reason could be that while patients with active progressive disease may be highly affected, patients with a steady state may be less affected by AA at the time of the questionnaire. Furthermore, the DLQI system is not designed specifically for AA, and therefore some of the questions for example, regarding itch, pain and physical activities are not suitable for assessing the impact of AA. Arguably, DLQI is an inappropriate measure to thoroughly assess quality of life related to AA, since it predominantly refers to cutaneous symptoms rather than symptoms associated with hair loss.

Although AA is neither life-threatening nor necessarily accompanied by physical pain, the condition may have a significant impact on patients' quality of life. A systematic review and meta-analysis summarised that the mean pooled DLQI score of patients with AA in three studies was 6.3 (95\% CI 5.6 to 7.1). ${ }^{21}$ Interestingly, a dose-response relationship between severity of AA and healthrelated quality of life is uncertain, ${ }^{21}$ possibly indicating that a small patch of hair loss may be just as impactful as a larger area of hair loss. Patients with AA may carry a significant psychological burden due to the visible loss of hair and the unpredictable disease course, which in turn may cause symptoms such as anxiety, depression, stress and sleep deprivation. ${ }^{22}{ }^{23}$ Hair loss may also carry a stigma relating to other forms of illnesses and oncologic chemotherapy.

\section{AA-specific patient-reported outcomes}

PROs related specifically to AA included information about eye irritation, missing eyelashes, missing eyebrows, damaged nails and missing scalp hair. Overall, most patients in our cohort did not experience irritated eyes $(55.7 \%)$, however nearly $30 \%$ reported slight eye irritation, $10.3 \%$ and $4.8 \%$ had moderate and severe eye irritation, respectively (table 3 ). Most patients either reported having full eyelashes $(43.6 \%)$ or no/barely no eyelashes $(32.2 \%)$ on each eyelid, and full eyebrows $(37.3 \%)$ or no/barely no eyebrow hairs $(36.2 \%)$. When rating the finger nails or toenails most patients (47.2\%) answered that the nails were not at all damaged (table 3 ). Notably however, most people $(31.4 \%)$ were missing nearly all or all scalp hair (95\%-100\% of the scalp is missing hair), suggesting that a high proportion of patients had severe scalp disease.

\section{AA diagnosis}

The mean (SD) time from onset of symptoms to diagnosis at a general practitioner (GP) was 1.0 (3.4) years (table 2). The majority of patients $(72.4 \%)$ reported that less than a year had passed from the first symptoms of AA until a diagnosis by the GP, while $17.9 \%$ and $9.7 \%$ reported more than 1 and 2 years delay, respectively. More than half of the patients $(66.9 \%)$ reported that they had symptoms of AA within the past 12 months. The mean (SD) current self-reported degree of AA was 7.4 (3.2) and the median (IQR) was 9 (5-10) on a NRS from 0 to 10.

GPs in Denmark are not trained in using methods such as trichoscopy, and to prevent misclassification of individuals with other forms of hair-loss, all patients included in our cohort had to be diagnosed with AA by a dermatologist. The relatively short time interval from onset of symptoms to contact with a GP indicates an urgency and need for diagnosis and intervention for patients with AA. Interestingly, the self-reported degree of AA was rather high (median 9), while on the other hand $46.9 \%$ of the patients reported that they were only missing $0 \%-20 \%$ of scalp hair. This observation suggests that the subjective burden of AA may not directly correlate with objective measures.

\section{Family history of AA}

When asked about history of AA in the family, approximately $5 \%$ reported that either a sibling or a parent had been diagnosed with AA. Furthermore, $4 \%$ and $3 \%$ reported that a grandparent or child had AA. A total of 179 patients $(12 \%)$ had at least one first degree family member with AA. An increased incidence of AA in firstdegree family members have previously been reported in up to $42 \%$ of patients. Furthermore, observational studies, twin studies and genome-wide association studies suggest a strong genetic component in pathogenesis of AA, similar to other autoimmune diseases. ${ }^{24} 25$ The family 
Table 3 AA-specific patient-reported outcomes

\section{Alopecia} areata

$n=1494$

(PRO measure for eye irritation) Please rate how irritated (eg, itching, stinging, burning or dry) either of your eyes have been in the past 7 days, $n(\%)$

$\begin{array}{lc}\text { My eyes have not been irritated } & 828(55.65) \\ \text { My eyes have been a little irritated } & 436(29.30) \\ \text { My eyes have been moderately irritated } & 153(10.28) \\ \text { My eyes have been severely irritated } & 71(4.77)\end{array}$

(PRO measure for eyelashes) Look at your upper and lower eyelashes on both your eyes. Please rate your eyelashes, as they look today, $\mathrm{n}(\%)$

\begin{tabular}{|c|c|}
\hline I have full eyelashes on each eyelid & $481(43.61)$ \\
\hline $\begin{array}{l}\text { I have a minimal gap or minimal gaps along } \\
\text { the eyelids }\end{array}$ & $203(18.40)$ \\
\hline $\begin{array}{l}\text { I have a large gap or large gaps along the } \\
\text { eyelids }\end{array}$ & $64(5.80)$ \\
\hline I have no or barely any eyelash hair & $355(32.18)$ \\
\hline \multicolumn{2}{|c|}{$\begin{array}{l}\text { (PRO measure for eyebrows) Look at the hair in both of your } \\
\text { eyebrows. Please rate your eyebrows, as they look today, } \mathrm{n}(\%)\end{array}$} \\
\hline I have full eyebrows on each eye & $412(37.25)$ \\
\hline $\begin{array}{l}\text { I have a minimal gap(s) or a minimal amount of } \\
\text { thinning in at least one of my eyebrows }\end{array}$ & $180(16.27)$ \\
\hline $\begin{array}{l}\text { I have a large gap(s) or a large amount of } \\
\text { thinning in at least one of my eyebrows }\end{array}$ & $114(10.31)$ \\
\hline I have no or barely any eyebrow hairs & $400(36.17)$ \\
\hline
\end{tabular}

(PRO measure for nail appearance) Examine your fingernails and toenails. Please rate your fingernails and toenails, as they look today, $\mathrm{n}(\%)$

Nails are not at all damaged (eg, pitted, rough, 522 (47.24) brittle, split)

At least one nail is a little damaged (eg, pitted, 303 (27.42) rough, brittle, split)

At least one nail is moderately damaged (eg, 193 (17.47) pitted, rough, brittle, split)

At least one nail is very damaged (eg, pitted, rough, brittle, split) or you have lost at least one nail

(Scalp hair assessment PRO) Use mirrors to look at your entire
scalp. Please rate the total area of your scalp that is missing
hair right now, $\mathrm{n}(\%)$
No missing hair ( $0 \%$ of my scalp is missing $234(21.16)$
hair; I have a full head of hair)
A limited area ( $1 \%-20 \%$ of my scalp is missing $284(25.68)$
hair)
A moderate area ( $21 \%-49 \%$ of my scalp is
missing hair)
$\begin{aligned} & \text { A large area ( } 50 \%-94 \% \text { of my scalp is missing } 11.93) \\ & \text { hair) }\end{aligned}$
$\begin{aligned} & \text { Nearly all or all ( } 95 \%-100 \% \text { of my scalp is } \\ & \text { missing hair) }\end{aligned}$

$\mathrm{AA}$, alopecia areata; $\mathrm{PRO}$, patient-reported outcome. history of AA may be underestimated in our cohort, as the condition is considered medically benign and patients with mild and/or transient symptoms may not have discussed it with their family members.

\section{STRENGTHS AND LIMITATIONS}

The AA extension in the Danish Skin Cohort represents a large group of patients with AA and provides an opportunity to investigate a range of variables and PROs longitudinally. The data may also be linked with routinely collected healthcare data from the nationwide Danish registries and gives us a unique opportunity to combine information on clinical manifestations of AA with pharmacological, sociodemographic data on individual-level. Patients were not interviewed about comorbidities, since information on comorbidities can be obtained on individual-level by linking patients questionnaire responses with our nationwide registries in Denmark. As with all questionnairebased studies, this cohort carries a risk of recall bias, however the majority of patients had symptoms within the past 12 months of participation, increasing the chance of a more accurate recollection. We expect a low risk of misclassification of patients, as all participants have been diagnosed by a dermatologist. We sought to reduce the risk of participation bias by not informing about the content of the project before accepting to participate, however it is likely that some demographic groups are better represented than others, resulting in a skewed gender and/or age distribution. The overall response rate was $46.7 \%$, which is in the normal range for surveys in Denmark. The DLQI data must be interpreted with caution, as the questionnaire is designed for 1 week recall period and some questions are more suitable for other skin conditions such as psoriasis rather than AA. Furthermore, data concerning Fitzpatrick skin type may not be extrapolated to countries with other ethnic compositions.

\section{COLLABORATION}

The AA cohort was established to bring new insight in disease characteristics as well as the impact of AA on different aspects of life including social, occupational and psychological behaviour. By adding longitudinal follow-up data, we hope to describe the disease trajectory and prognosis of AA, as well as explore the burden of disease over time. Furthermore, by adding routinely collected data, we will be able to investigate comorbidities and efficacy of pharmacological interventions. A deepened and more holistic understanding of AA will hopefully increase awareness of the disorder and facilitate personalised treatment strategies. Future collaboration projects with other research groups are of interest, especially collaborations where study results may be replicated in other cohorts internationally.

Contributors YMFA, LN, AMD, RB, EE-H: conception and design, planning, interpretation of data and reporting of the work. AE: conception, design, planning, 
conduct, acquisition, analysis and interpretation of data, reporting of the work. AE acts as the guarantor.

Funding Development of this manuscript was supported by Eli Lilly and Company.

Competing interests Dr YMFA has received research funding from $\mathrm{Kgl}$ Hofbundtmager Aage Bang Foundation and AP Moller Foundation. Ms. LN has nothing to declare. Dr RTB, Mrs. AMD and Mrs. EE-H are employees and stockholders of Eli Lilly and Company. Dr AE has received research funding from Pfizer, Eli Lilly, Novartis, Bristol-Myers Squibb, AbbVie, Janssen Pharmaceuticals, the Danish National Psoriasis Foundation, the Simon Spies Foundation and the $\mathrm{Kgl}$ Hofbundtmager Aage Bang Foundation and honoraria as consultant and/or speaker from AbbVie, Almirall, Leo Pharma, Galápagos NV, Sun Pharmaceuticals, Samsung Bioepis, Ltd, Pfizer, Eli Lilly and Company, Novartis, Galderma, Dermavant, UCB, Mylan, Bristol-Myers Squibb and Janssen Pharmaceuticals.

Patient consent for publication Not required.

Ethics approval This study involves human participants but was not approved. Review of an ethics committee is not required in Denmark for studies not involving human tissue. Participants gave informed consent to participate in the study before taking part.

Provenance and peer review Not commissioned; externally peer reviewed.

Data availability statement Data are available upon reasonable request. There are no plans on sharing the raw data, however, data from the Danish Skin Cohort will be available for research collaborations upon obtaining the necessary legal approvals.

Supplemental material This content has been supplied by the author(s). It has not been vetted by BMJ Publishing Group Limited (BMJ) and may not have been peer-reviewed. Any opinions or recommendations discussed are solely those of the author(s) and are not endorsed by BMJ. BMJ disclaims all liability and responsibility arising from any reliance placed on the content. Where the content includes any translated material, BMJ does not warrant the accuracy and reliability of the translations (including but not limited to local regulations, clinical guidelines, terminology, drug names and drug dosages), and is not responsible for any error and/or omissions arising from translation and adaptation or otherwise.

Open access This is an open access article distributed in accordance with the Creative Commons Attribution Non Commercial (CC BY-NC 4.0) license, which permits others to distribute, remix, adapt, build upon this work non-commercially, and license their derivative works on different terms, provided the original work is properly cited, appropriate credit is given, any changes made indicated, and the use is non-commercial. See: http://creativecommons.org/licenses/by-nc/4.0/.

ORCID iD

Alexander Egeberg http://orcid.org/0000-0001-8257-1816

\section{REFERENCES}

1 Mirzoyev SA, Schrum AG, Davis MDP, et al. Lifetime Incidence Risk of Alopecia Areata Estimated at $2.1 \%$ by Rochester Epidemiology Project, 1990-2009. J Invest Dermatol 2014;134:1141-2.

2 Villasante Fricke AC, Miteva M. Epidemiology and burden of alopecia areata: a systematic review. Clin Cosmet Investig Dermatol 2015;8:397-403.

3 Gilhar A, Etzioni A, Paus R. Alopecia areata. N Engl J Med 2012;366:1515-25

4 Chu S-Y, Chen Y-J, Tseng W-C, et al. Comorbidity profiles among patients with alopecia areata: the importance of onset age, a nationwide population-based study. J Am Acad Dermatol 2011;65:949-56.

5 Strazzulla LC, Wang EHC, Avila L, et al. Alopecia areata: disease characteristics, clinical evaluation, and new perspectives on pathogenesis. J Am Acad Dermatol 2018;78:1-12.

6 Islam N, Leung PSC, Huntley AC, et al. The autoimmune basis of alopecia areata: a comprehensive review. Autoimmun Rev 2015;14:81-9.

7 Egeberg A, Andersen YMF, Thyssen JP. Prevalence and characteristics of psoriasis in Denmark: findings from the Danish skin cohort. BMJ Open 2019;9:e028116.

8 Schmidt M, Schmidt SAJ, Sandegaard JL, et al. The Danish national patient registry: a review of content, data quality, and research potential. Clin Epidemiol 2015;7:449-90.

9 Wyrwich KW, Kitchen H, Knight S, et al. Development of the scalp hair assessment PRO ${ }^{\mathrm{TM}}$ measure for alopecia areata. Br. J. Dermatol. 2020;183:1065-72.

10 Kyriakis KP, Paltatzidou K, Kosma E, et al. Alopecia areata prevalence by gender and age. J Eur Acad Dermatology Venereol 2009;23:572-3.

11 Ö A, Koyuncu Z, Serdaroğlu S. Association of alopecia with selfesteem in children and adolescents. Int J Adolesc Med Health2020;1.

12 Egeberg A, Griffiths CEM, Williams HC, et al. Clinical characteristics, symptoms and burden of psoriasis and atopic dermatitis in adults. $\mathrm{Br}$ J Dermatol 2020;183:128-38.

13 Gwillim EC, Jimenez J, Ali Y, et al. 205 risk of ischemic heart disease in patients with alopecia areata: a large, urban, retrospective midwestern us patient population study. J Invest Dermatol 2019;139:S35.

14 Huang KP, Joyce CJ, Topaz M, et al. Cardiovascular risk in patients with alopecia areata (AA): a propensity-matched retrospective analysis. J Am Acad Dermatol 2016;75:151-4.

15 Kang J-H, Lin H-C, Kao S, et al. Alopecia areata increases the risk of stroke: a 3-year follow-up study. Sci Rep 2015;5:1-6.

16 Dai Y-X, Yeh F-Y, Shen Y-J, et al. Cigarette smoking, alcohol consumption, and risk of alopecia areata: a population-based cohort study in Taiwan. Am J Clin Dermatol 2020;21:901-11.

17 Lee H, Jung SJ, Patel AB, et al. Racial characteristics of alopecia areata in the United States. J Am Acad Dermatol 2020;83:1064-70.

18 Thompson JM, Park MK, Qureshi AA, et al. Race and Alopecia Areata amongst US Women. J Investig Dermatology Symp Proc 2018;19:S47-50.

19 Roberts MH, Erdei E. Comparative United States autoimmune disease rates for $2010-2016$ by sex, geographic region, and race. Autoimmun Rev 2020;19:102423.

20 Moroni L, Bianchi I, Lleo A. Geoepidemiology, gender and autoimmune disease. Autoimmun Rev 2012;11:A386-92.

21 Rencz F, Gulácsi L, Péntek M, et al. Alopecia areata and healthrelated quality of life: a systematic review and meta-analysis. $\mathrm{Br} \mathrm{J}$ Dermatol 2016;175:561-71.

22 Okhovat J-P, Marks DH, Manatis-Lornell A, et al. Association between alopecia areata, anxiety, and depression: a systematic review and meta-analysis. J Am Acad Dermatol 2019. doi:10.1016/j.jaad.2019.05.086. [Epub ahead of print: 01 Jun 2019].

23 Dai $\mathrm{Y}-\mathrm{X}$, Tai $\mathrm{Y}-\mathrm{H}$, Chen $\mathrm{C}-\mathrm{C}$, et al. Bidirectional association between alopecia areata and sleep disorders: a population-based cohort study in Taiwan. Sleep Med 2020;75:112-6.

24 Biran R, Zlotogorski A, Ramot Y. The genetics of alopecia areata: new approaches, new findings, new treatments. J Dermatol Sci 2015;78:11-20.

25 Petukhova L, Duvic M, Hordinsky M, et al. Genome-Wide association study in alopecia areata implicates both innate and adaptive immunity. Nature 2010;466:113-7. 